\title{
Maternal Fluoxetine Exposure Alters Cortical Hemodynamic and Calcium Response of Offspring to Somatosensory Stimuli
}

\author{
[Dachel M. Rahn, ${ }^{1,2,3}$ @Susan E. Maloney, ${ }^{3,4}$ Lindsey M. Brier, ${ }^{1}$ Joseph D. Dougherty, ${ }^{2,3,4}$ and Joseph \\ P. Culver ${ }^{1,5,6}$
}

https://doi.org/10.1523/ENEURO.0238-19.2019

${ }^{1}$ Department of Radiology, Washington University School of Medicine, St. Louis, MO 63110, ${ }^{2}$ Department of Genetics, Washington University School of Medicine, St. Louis, MO 63110, ${ }^{3}$ Department of Psychiatry, Washington University School of Medicine, St. Louis, MO 63110, ${ }^{4}$ Intellectual and Developmental Disabilities Research Center, Washington University School of Medicine, St. Louis, MO 63110, ${ }^{5}$ Department of Biomedical Engineering, Washington University, St. Louis, MO 63110, and ${ }^{6}$ Department of Physics, Washington University, St. Louis, MO 63110

\begin{abstract}
Epidemiological studies have found an increased incidence of neurodevelopmental disorders in populations prenatally exposed to selective serotonin reuptake inhibitors (SSRIs). Optical imaging provides a minimally invasive way to determine if perinatal SSRI exposure has long-term effects on cortical function. Herein we probed the functional neuroimaging effects of perinatal SSRI exposure in a fluoxetine (FLX)-exposed mouse model. While resting-state homotopic contralateral functional connectivity was unperturbed, the evoked cortical response to forepaw stimulation was altered in FLX mice. The stimulated cortex showed decreased activity for FLX versus controls, by both hemodynamic responses [oxyhemoglobin $\left(\mathrm{HbO}_{2}\right)$ ] and neuronal calcium responses (Thy1-GCaMP6f fluorescence). Significant alterations in both cortical $\mathrm{HbO}_{2}$ and calcium response amplitude were seen in the cortex ipsilateral to the stimulated paw in FLX as compared to controls. The cortical regions of largest difference in activation between FLX and controls also were consistent between $\mathrm{HbO}_{2}$ and calcium contrasts at the end of stimulation. Taken together, these results suggest a global loss of response signal amplitude in FLX versus controls. These findings indicate that perinatal SSRI exposure has long-term consequences on somatosensory cortical responses.
\end{abstract}

Key words: calcium imaging; cerebral hemodynamics; fluoxetine; serotonin; somatosensory;

\section{Significance Statement}

Use of selective serotonin reuptake inhibitors (SSRIs) by pregnant women has increased in the past decades, raising questions regarding the long-term effects of SSRI usage during pregnancy on offspring. In order to isolate the effect of perinatal SSRI exposure from genetic variables or a maternal psychiatric diagnosis, we used in vivo functional neuroimaging to examine adult cortical function both at rest and in response to a somatosensory input in a mouse model of perinatal SSRI exposure. Our mouse model displayed no global disruption of brain function at rest when compared to controls, while its cortical response to a somatosensory stimulus was reduced, as measured by both hemodynamics and excitatory calcium signaling.

\section{Introduction}

The serotonin $(5 \mathrm{HT})$ system and its proper development are critical to typical neurologic function, and implicated in

Received June 18, 2019; accepted November 17, 2019; First published December 16, 2019.

The authors declare no competing financial interests. a variety of neurodevelopmental processes and psychiatric conditions (Vitalis and Parnavelas, 2003; O'Connell et al., 2018). 5HT modulation is a common target for 
pharmaceuticals such as selective serotonin reuptake inhibitors (SSRIs), which are widely used for the treatment of depression and anxiety (Linde et al., 2015), including in an increasing proportion of pregnant women (Cooper et al., 2007; Mitchell et al., 2011).

It is known that $5 \mathrm{HT}$ also plays key roles in brain development (Vitalis and Parnavelas, 2003; Sodhi and Sanders-Bush, 2004). At fetal stages, $5 \mathrm{HT}$ receptors are already localized in the human thalamus (Wai et al., 2011), and are required for proper development of sensory gating circuits (McCormick and Bal, 1994). The 5HT transporter is also transiently expressed in thalamocortical axons during development (Lebrand et al., 1996; Bonnin et al., 2007), and altered 5HT activity, including that achieved with early SSRI exposure, has been linked to morphologic changes in the rat somatosensory cortex and its thalamocortical afferents (Lee, 2009). However, an important question remains whether the presence of SSRIs during brain development alters somatosensory connectivity specifically, or brain development generally, in a manner that has long-term consequences.

Despite the increase in SSRI usage in pregnant women, the full long-term effects of perinatal SSRI exposure are unclear. Long-term developmental and emotional alterations, such as increased anxiety (Lupattelli et al., 2018) and depression (Malm et al., 2016; Liu et al., 2017) diagnoses, have been observed in populations prenatally exposed to SSRIs. Altered behavioral responses to pain (Oberlander et al., 2002, 2005) and poor neonatal adaption (Olivier et al., 2013) have also been noted in SSRIexposed infants. There is a lack of consensus regarding whether some behavioral alterations can be directly linked to prenatal SSRI exposure or if maternal psychiatric stress plays a major role (Oberlander et al., 2007; Hanley et al., 2015; Lupattelli et al., 2018). There also exists a lack of data available regarding postpubertal effects. Because human behavior is difficult to directly link to neural perturbations, more immediate quantifiable phenotypes might be obtainable through brain imaging.

Human brain imaging outcomes suggest both structural and functional abnormalities in the perinatally-exposed population. Compared to controls or infants with depressed mothers, neonates with SSRI-treated mothers displayed increased gray matter volume and white matter connectivity in the amygdala and insula (Lugo-Candelas et al., 2018). Functional neuroimaging studies observed con-

R.M.R. is supported by the National Institute of Neurological Disorders and Stroke (NINDS) Grant F31 NS110222 and has been supported by the National Institute of General Medical Sciences Grant T32 GM081739; the J.D.D. lab is supported by The Simons Foundation and National Institute of Mental Health Grants R01 MH107515, R01 MH116999, and U01 MH109133; and J.P.C. lab is supported by NINDS Grants R01 NS078223 and R01 NS099429 and by the National Institute of Child Health and Human Development Grant U54HD087011.

Correspondence should be addressed to Rachel M. Rahn at rrahn@wustl.edu.

https://doi.org/10.1523/ENEURO.0238-19.2019

Copyright () 2019 Rahn et al.

This is an open-access article distributed under the terms of the Creative Commons Attribution 4.0 International license, which permits unrestricted use, distribution and reproduction in any medium provided that the original work is properly attributed. nectivity increases in infants' auditory resting-state network following prenatal SSRI exposure (Rotem-Kohavi et al., 2019) and reduced interhemispheric connectivity in EEG studies (Videman et al., 2017). However, functional neuroimaging studies have not yet explored the effects of perinatal SSRI exposure after the neonatal period or used task-based studies to determine potential alterations in sensory inputs. Human studies of perinatal SSRI exposure are also complicated by the genetic and environmental heterogeneity that is intrinsic in any human population, as well as the confounding influence of maternal diagnosis.

To ameliorate some of these problems, mouse models provide an avenue to study the biological impact of one isolated manipulation such as perinatal SSRI exposure in a controlled genetic background and environment. In rodent models, early developmental SSRI exposure has been associated with increased depression-like and anxiety-like behavior (Hansen et al., 1997; Ansorge, 2004; Gingrich et al., 2017), as well as alterations in somatosensory-related behaviors (Lee, 2009; Maloney et al., 2018). Early postnatal SSRI exposure in rats reduced dendritic complexity of Layer V pyramidal neurons in motor cortex (Lee and Lee, 2012) and of thalamocortical afferents and Layer IV spiny stellate neurons in somatosensory cortex (Lee, 2009). Prenatal fluoxetine (FLX) exposure also reduced dendritic complexity of layer $2 / 3$ pyramidal neurons in $\mathrm{P} 6-\mathrm{Pg}$ mouse somatosensory cortex and remained even up to 16 months of age (Smit-Rigter et al., 2012). There however remains a lack of functional neuroimaging literature examining SSRI exposure models that bridges the gap between morphologic and behavioral abnormalities.

We therefore imaged a mouse model of perinatal SSRI exposure in vivo to characterize adult cortical function both at rest and following sensory input. Because of the close relationship between $5 \mathrm{HT}$, SSRIs, and thalamocortical projection development, we examined whether functional neuroimaging of a perinatal SSRI exposure model would uncover functional disruption globally as well as specifically in somatosensory cortex, a region uniquely vulnerable to SSRIs. We found that our mouse model of early SSRI exposure displayed resting-state functional connectivity similar to controls, yet exhibited a reduced cortical response to somatosensory stimulation as quantified by both hemodynamics and excitatory calcium signaling.

\section{Materials and Methods}

\section{Animal preparation}

All procedures using mice were approved by the Washington University Institutional Animal Care and Use Committee and conducted in accordance with the approved Animal Studies Protocol. Mice were housed in translucent plastic cages measuring $28.5 \times 17.5 \times 12 \mathrm{~cm}$ with corncob bedding and standard lab diet and water freely available. The colony room lighting was a 12/12 h light/dark cycle, and the room temperature $\left(\sim 20-22^{\circ} \mathrm{C}\right)$ and relative humidity (50\%) were controlled automatically.

Following the previously published description of a perinatal SSRI exposure model (Maloney et al., 2018), mouse dams were exposed to the SSRI FLX through 
Table 1. Statistical summary for Figures 1-Figures 4

\begin{tabular}{|c|c|c|c|c|}
\hline Figures & Data structure & Type of test & $n$ & Statistical significance \\
\hline $1 F$ & Normal & Student's $t$ test & $n=48 \mathrm{FLX}, 42 \mathrm{VEH}$ & $p>0.05$ with Bonferroni correction \\
\hline $1 J$ & Normal & Student's $t$ test & $n=34 \mathrm{FLX}, 25 \mathrm{VEH}$ & $p>0.05$ with Bonferroni correction \\
\hline 21 & Non-normal & Wilcoxon rank-sum test & $n=30 \mathrm{FLX}, 24 \mathrm{VEH}$ & $\begin{array}{l}\text { Contralateral HbO: } p=0.13 \\
\text { ipsilateral HbO: } p=0.0046 ; \\
\text { Contralateral GCAMP6F: } p=0.060 ; \\
\text { ipsilateral GCAMP6F: } p=0.0011\end{array}$ \\
\hline 21 & Non-normal & Wilcoxon rank-sum test & $n=18 \mathrm{FLX}, 11 \mathrm{VEH}$ (males) & $\begin{array}{l}\text { Contralateral HbO: } p=0.14 \\
\text { ipsilateral HbO: } p=0.010 \\
\text { contralateral GCAMP6F: } p=0.06 \\
\text { ipsilateral GCAMP6F: } p=0.038\end{array}$ \\
\hline 21 & Non-normal & Wilcoxon rank-sum test & $n=12 \mathrm{FLX}, 13 \mathrm{VEH}$ (females) & $\begin{array}{l}\text { Contralateral HbO: } p=0.23 \\
\text { ipsilateral HbO: } p=0.13 \\
\text { contralateral GCAMP6F: } p=0.36 \\
\text { ipsilateral GCAMP6F: } p=0.012\end{array}$ \\
\hline $3 D$ & Non-normal & Wilcoxon rank-sum test & $n=30 \mathrm{FLX}, 24 \mathrm{VEH}$ & $\begin{array}{l}\text { Contralateral HbO: } p=0.050 \\
\text { ipsilateral HbO: } p=0.043 \\
\text { contralateral GCAMP6F: } p=0.028 \\
\text { ipsilateral GCAMP6F: } p=0.014\end{array}$ \\
\hline $3-1 A, C$ & Non-normal & Wilcoxon rank-sum test & $n=18 \mathrm{FLX}, 11 \mathrm{VEH}$ (males) & $\begin{array}{l}\text { Contralateral HbO: } p=0.031 \\
\text { ipsilateral HbO: } p=0.15 \\
\text { contralateral GCAMP6F: } p=0.034 ; \\
\text { ipsilateral GCAMP6F: } p=0.34\end{array}$ \\
\hline $3-1 B, D$ & Non-normal & Wilcoxon rank-sum test & $n=12 \mathrm{FLX}, 13 \mathrm{VEH}$ (females) & $\begin{array}{l}\text { Contralateral HbO: } p=0.12 \\
\text { ipsilateral HbO: } p=0.075 \\
\text { contralateral GCAMP6F: } p=0.32 \\
\text { ipsilateral GCAMP6F: } p=0.0042\end{array}$ \\
\hline $4 C$ & Normal & Student's $t$ test & $n=30 \mathrm{FLX}, 24 \mathrm{VEH}$ & $p<0.05$ for regions displayed \\
\hline
\end{tabular}

drinking water (48 mg/d in 1\% saccharin water) beginning immediately before gestation and ending at pup postnatal day 14. This exposure time period and dosage were chosen to replicate the effects of usage of the maximum recommended human dose of FLX (Marken and Munro, 2000) and to mirror the period of human pregnancy and early life breastfeeding, as the final trimester of human pregnancy is equivalent to the first week of life in a murine mouse model, and the remaining week (postnatal days 8-14) during which the pups were exposed through their mother's milk mirrors a postbirth breastfeeding period. The dose used was equivalent to the maximum recommended human dose of $80 \mathrm{mg} / \mathrm{d}$ (Maloney et al., 2018). Vehicle (VEH)-exposed dams received only $1 \%$ saccharin drinking water. Dams were randomly assigned to treatment groups.

Male and female adult mice (11-22 weeks of age), age-matched at imaging and from multiple independent litters of FLX and VEH dams, were used for imaging and processed in five independent cohorts (cohort 1: $n=7$ FLX, 8 VEH; cohort 2: $n=8$ FLX, $10 \mathrm{VEH;} \mathrm{cohort} \mathrm{3:} n=$ $9 \mathrm{FLX}, 8 \mathrm{VEH}$; cohort 4: $n=9$ FLX, 8 VEH; cohort $5: n=$ $17 \mathrm{FLX}, 11 \mathrm{VEH})$. Both FLX and VEH groups included mice of both sexes (see Table 1 for number of males and females used in sex-specific analyses). Because this is a novel study without a prior basis for effect size, a power analysis using a standard estimated large effect size of 0.8 and with $80 \%$ power indicated a total sample size of 42 animals is required to reject the null hypothesis at the $0.05 \alpha$ level. Mice were imaged during their 6 A.M. to 6 P.M. light cycle, with FLX and VEH mice counterbalanced across the imaging day. The health of the animals was monitored, and no differences between groups was observed. The experimenter was blinded to the treatment condition during data acquisition, processing, and preliminary analysis. Mice were excluded from analysis if movement of the animal suggesting wakefulness was detected, or from evoked response analysis if stimulation application failed and no change from baseline was recorded. The first two cohorts were wild type C57BL6/J (JAX: 000664), while the later three were Thy1-GCaMP6f on the C57BL6/J background (JAX:024276). GCaMP6f expression allowed for population-based calcium recording from cortical excitatory neurons, in addition to concurrently acquired hemodynamics. All mice were fitted with a transparent Plexiglas window to facilitate imaging. Briefly, mice were sedated using isoflurane $(3 \%$ induction, $1 \%$ maintenance, $0.5 \mathrm{l} / \mathrm{min}$ ) with body temperature maintained at $37^{\circ} \mathrm{C}$ using a heating pad; the head was then shaved and the mouse prepared for surgery in a stereotactic restraint. An incision in the scalp was made along midline to expose the skull, and the skin was retracted to expose an $\sim 1-\mathrm{cm}^{2}$ cortical field of view through the skull. A cranial window of Plexiglas was affixed to the dorsal surface of the intact skull using dental cement (C\&B-Metabond, Parkell Inc.) which allowed for chronic, repeatable imaging.

After a minimum of $48 \mathrm{~h}$ of postsurgery recovery, the mice were anesthetized for imaging by intraperitoneal injection of a ketamine/xylazine cocktail $(86.9 \mathrm{mg} / \mathrm{kg}$ ketamine, $13.4 \mathrm{mg} / \mathrm{kg}$ xylazine, dosage $0.005 \mathrm{ml} / \mathrm{kg}$ ) to avoid burst suppression (Ferron et al., 2009), and maintained at $37^{\circ} \mathrm{C}$ by heating pad (mTCII, Cell Microcontrols). Insertion of the mouse into the imaging apparatus was not initiated until full transition to the anesthetized state was observed, 
A

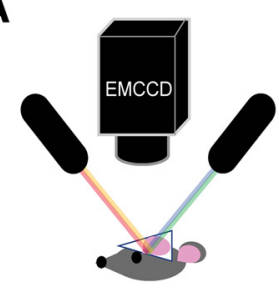

B
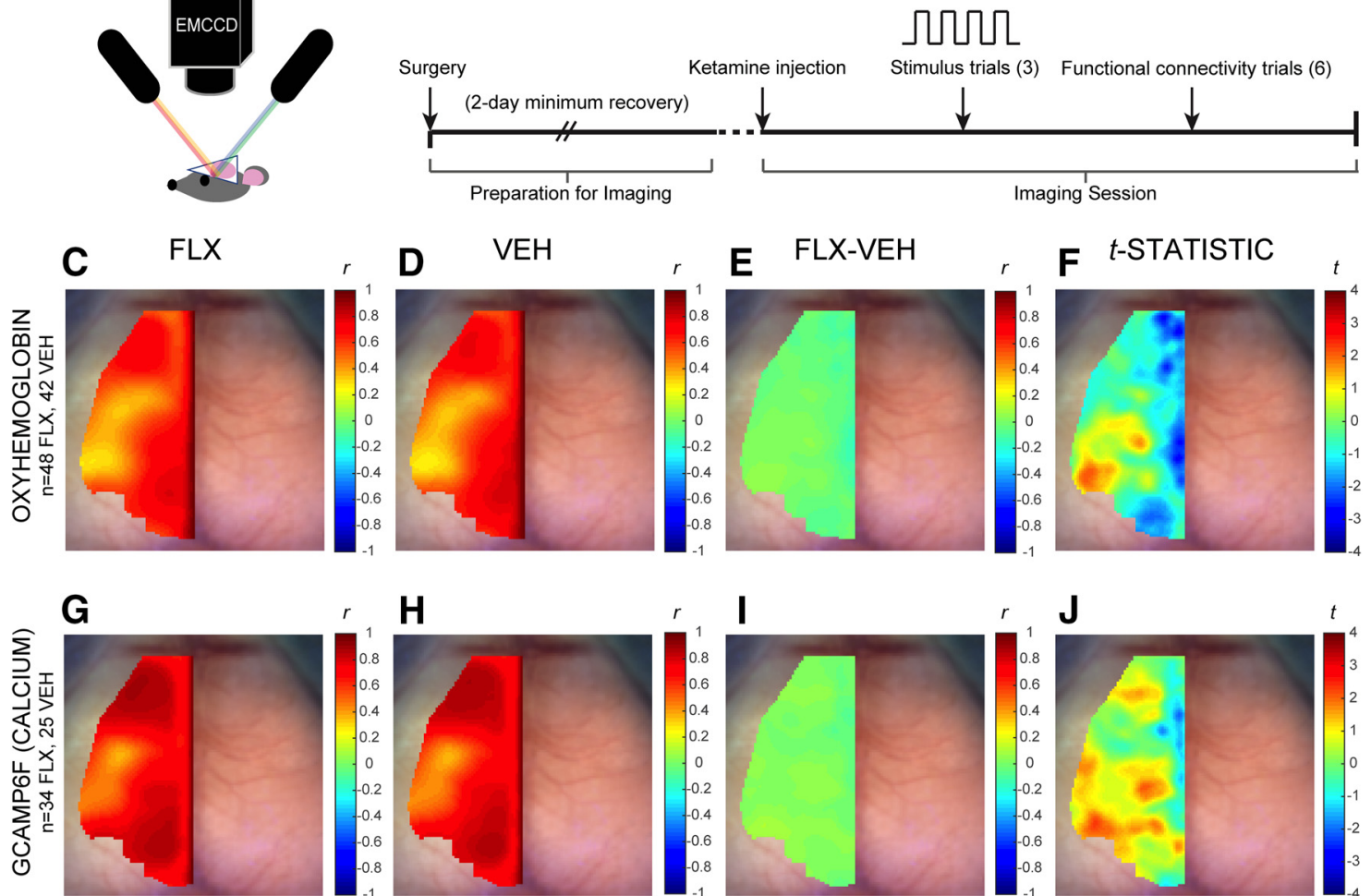

$\mathbf{H}$
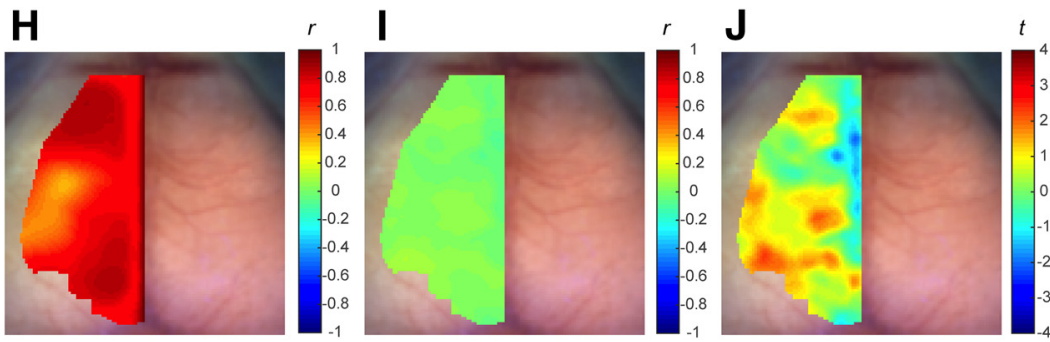

Figure 1. Resting-state homotopic contralateral functional connectivity in FLX mice does not significantly differ from VEH controls. $\boldsymbol{A}$, Optical fluorescence/OIS imaging system schematic: The cranial window lies directly below the camera as sequential illumination is delivered from light sources nearby. See Extended Data Figure 1-1 for a representative mouse brain image in which pixels not containing brain tissue are excluded from analysis and brain landmarks are identified. $\boldsymbol{B}$, Representation of OIS and evoked response imaging workflow. $\boldsymbol{C}-\boldsymbol{F}$, Map of mean $\mathrm{HbO}_{2}$ homotopic contralateral functional connectivity (Pearson's $\left.r\right)$ in $(\boldsymbol{C}) \mathrm{FLX}(n=48)$ and $(\boldsymbol{D})$ VEH $(n=42)$ groups. $\boldsymbol{E}$, Mean difference between FLX and VEH $\Delta \mathrm{HbO}_{2}$ maps (FLX-VEH). $\boldsymbol{F}, t$ statistic map of FLX-VEH groups (uncorrected). G-J, Map of mean GCaMP6f $(\Delta \mathrm{F})$ homotopic contralateral functional connectivity (Pearson's $r)$ in $(\boldsymbol{G})$ FLX $(n=34)$ and $(\boldsymbol{H})$ VEH $(n=25)$ groups. I, Mean difference between FLX and VEH GCaMP6f maps (FLX-VEH). $\boldsymbol{J}$, $t$ statistic map of FLX-VEH groups (uncorrected).

as measured by the absence of whisker movement or a response to a toe-pinch stimulus. The mouse's head and imaging plane were secured using a platform mount which attached to and stabilized the Plexiglas window adhered to the mouse's skull.

\section{Optical imaging system}

Sequential illumination was provided at four wavelengths by a ring of light-emitting diodes (LEDS: 478, 588, 610, and $625 \mathrm{~nm}$; RLS-5B475-S, B5B-4343-TY, B5B435-30S, and OSCR5111A-WY, respectively; Roithner Lasertehnik) $\sim 10 \mathrm{~cm}$ above the mouse's head, following the methods of White et al. (2011). Diffuse reflected light was captured by a cooled, frame-transfer EMCCD camera (iXon 897, Andor Technologies). Acquisition was synchronized with the LEDs' sequential illumination and controlled via custom-written software (MATLAB, MathWorks) at a frame rate of $30 \mathrm{~Hz}$ per LED. The field of view was $\sim 1 \mathrm{~cm}^{2}$ with an anterior-posterior view from olfactory bulb to superior colliculus, consisting of $128 \times 128$ pixels with pixel size of $\sim 80 \mu \mathrm{m}^{2}$. Cohorts 1 and 2 were imaged on this system.

\section{Optical/calcium fluorescence imaging system}

Sequential illumination and fluorophore excitation was provided by four LEDs situated $\sim 8 \mathrm{~cm}$ above the head [454 (GCaMP excitation), 523, 595, and $640 \mathrm{~nm}$ ], following the methods of Wright et al. (2017; Fig. 1A). Diffuse reflected light and fluorescence emission was captured by a cooled, frame-transfer EMCCD camera (iXon 897, Andor Technologies). Acquisition was synchronized with the LEDs' sequential illumination and controlled via customwritten software (MATLAB, MathWorks) at a frame rate of $\sim 16 \mathrm{~Hz}$ per LED. The field of view was $\sim 1 \mathrm{~cm}^{2}$ with an anterior-posterior view from olfactory bulb to superior colliculus consisting of an image plane sampled by $512 \times$ 512 pixels, which are binned $4 \times 4$ down to $128 \times 128$ pixels with on-chip binning. The resulting pixel size was $\sim 80 \mu \mathrm{m}^{2}$ on the mouse head. Cohorts $3-5$ were imaged on this system.

\section{Functional connectivity}

Functional connectivity data under anesthesia and without stimulation (referred to here as resting state) was collected in each mouse for up to $30 \mathrm{~min}$, split into six consecutive runs of $5 \mathrm{~min}$ (Fig. 1B). The first resting state 
run for each mouse was initiated approximately 3 min following any stimulus application from previous data collection blocks. Visual monitoring of the mouse was performed throughout, and on the detection of whisking or other movement indicating a return to wakefulness, the imaging session was terminated and the mouse was removed from the imaging system to complete its emergence from the anesthetized state.

\section{Forepaw stimulation}

Electrical pulses were generated by an isolated pulse stimulator (Modell 2100, A-M Systems) and administered to the left forepaw by micro vascular clips (Roboz Surgical Instrument Co.). Stimulation data were collected in three consecutive runs of $5 \mathrm{~min}$ each. The block design was modeled on existing $\mathrm{fMRl}$ and functional optical imaging stimulation studies, in which mixed blocks of stimulation and resting state are common. Although some fMRI studies have shown a subtle alteration of resting state due to prior motor learning tasks (Albert et al., 2009; Zhang et al., 2014), these effects have not been explored as extensively with mice and optical intrinsic signal (OIS). In either case, in this study we used the same design structure for both groups of mice and thus the effect or lack of effect would equally influence both groups. The 5-min run consisted of five 1-min blocks; each with an initial 5-s rest period, followed by $10 \mathrm{~s}$ of electrical stimulation (frequency: $3 \mathrm{~Hz}$, pulse duration: $300 \mu \mathrm{s}$, current: $0.75 \mathrm{~mA}$ ), and $45 \mathrm{~s}$ of rest (Fig. $1 \mathrm{~A}$ ). The five 1-min blocks were later block averaged for each stimulus trial.

\section{Imaging data processing and analysis}

Data were processed using MATLAB and an imaging analysis pipeline following that previously described in the literature (Bauer et al., 2014; Wright et al., 2017) with modifications as described. For calcium imaging, approximated absorption coefficients for GCaMP6 excitation and emission were calculated and used to correct for absorption of GCaMP6 fluorescence by hemodynamic fluctuations, as described elsewhere (Ma et al., 2016). For all cohorts, a binary brain mask was created by delineating brain borders in the field of view using the roipoly function in MATLAB. Following a previously published approach (White et al., 2011), the co-registration processing began with defining an individual-specific binary brain mask that was created for each mouse and used to eliminate pixels not containing brain tissue (Extended Data Fig. 1-1). Within the mouse images, we manually labeled the locations of lambda, where superior colliculus and cerebrum intersect at midline, and the anterior suture between the olfactory bulb and cerebrum at midline. These coordinates were then used to co-register all mice to common Paxinos atlas space (Franklin and Paxinos, 2008) using a two-dimensional affine transformation. Runs with light levels with $>1 \%$ variance throughout the time series were discarded. In addition to visual inspection, movement of the animal was tracked by calculating pixel displacement for each run, and runs with detected movement were subsequently discarded. The runs which passed these quality-control steps were used to create average functional connectivity maps or stimulus time traces for each mouse. After quality control, for resting state analysis an average of $70 \%$ of the data per mouse was used, with a minimum requirement of 5 min of data from each mouse. For stimulation an average of $80 \%$ of the data per mouse was used, with a minimum of $5 \mathrm{~min}$ (five stimulation presentations) of data from each mouse.

The processed resting-state functional connectivity and evoked-response data produced were used to analyze homotopic contralateral function connectivity (HCFC) and change from baseline oxyhemoglobin $\left(\Delta \mathrm{HbO}_{2}\right)$ or fluorescence $(\Delta \mathrm{F})$ levels across time, respectively. Resting-state analyses included hemodynamic data from cohorts 1-5 to maximize sample size, and calcium data from the GCaMP-positive cohorts, cohorts 3-5. The forepaw stimulation analyses used cohorts 1 and 2 to define regions of interests (ROIs), which were then used to subsequently analyze the hemodynamic and calcium response data from cohorts $3-5$. Figure $1 C-F$ includes more mice than Figure $1 G-J$ because Figure $1 C-F$ has hemodynamic measures and includes the data of cohorts 1-5 to include the maximum sample size. Figure $1 G-J$ includes less mice because it is a calcium measure and cohorts 1-2 were GCaMP-negative and therefore had no fluorophore excitation to record and average into the functional connectivity maps.

Hemodynamic data were filtered to the 0.009- to $0.25-\mathrm{Hz}$ band (stimulation data) or $0.009-$ to $0.08-\mathrm{Hz}$ band (resting-state data), whereas calcium signal was filtered to the 0.1 - to $6.0-\mathrm{Hz}$ band (stimulation data) or $0.4-$ to $4.0-\mathrm{Hz}$ band (resting-state data). Global signal regression was performed on all data to remove sources of variance, except where indicated otherwise. An averaged map of pixel-by-pixel comparisons of HCFC for each mouse was produced by use of the brain mask and atlas-based midline coordinates. Because the homotopic contralateral connectivity methods compare pairs of pixels that are reflections of each other between the left and right hemisphere, the left and right hemisphere maps are mirror images about midline. We therefore report via heat map the connectivity coefficients in the left hemisphere and display the dorsal cortical surface and its landmarks on the right hemisphere, to provide anatomic context when viewing the values displayed across midline.

Forepaw stimulation data were analyzed both across time and at stimulus end (the mean of 11 frames surrounding $t=10 \mathrm{~s}$ ). Each stimulus block was normalized to mean baseline hemoglobin or calcium levels in the $5 \mathrm{~s}$ before stimulus onset. To calculate change in hemoglobin or calcium levels across time in cohorts $3-5$, two ROls were defined using the independent $t$ statistic map derived from cohorts 1 and 2's FLX-VEH differences at stimulus end (Extended Data Fig. 2-1). A circle $(r=15$ pixels or $\sim 1.2 \mathrm{~mm}$ ) centered on the maximum $\mathrm{HbO}_{2}$ value in stimulated right (contralateral) cortex was drawn to produce one $\mathrm{ROI}$, then reflected across midline to create a homotopic ROI in left (ipsilateral) cortex. All halfmaximum $t$ statistic pixels in the contralateral region and half-minimum $t$ statistic pixels in ipsilateral region were identified (Extended Data Fig. 2-1D), and the time traces of these pixels within each of the two regions (contralat- 
eral and ipsilateral) were averaged and plotted across time. Pearson $r$ values were Fisher $z$-transformed before all mathematical operations.

\section{Statistical analysis}

All statistical comparisons were performed using MATLAB v9.2 (MathWorks). Statistical analyses were performed to determine if there was a significant difference between FLX and VEH groups in stimulation and restingstate trials. Statistical significance was determined by two-tailed unpaired Student's $t$ tests in all instances except where otherwise stated. For HCFC analyses, a $t$ test was performed for each brain pixel pair and represented by a heat map value in that pixel within the cortical image. With the data smoothed by a Gaussian blur with full width at half maximum of $0.096 \mathrm{~mm}$, and a field of view of 22.9 $\mathrm{mm}^{2}$, an estimated 792 independent measures exist. The minimum uncorrected $p$ value is $0.0015\left(\mathrm{HbO}_{2}\right)$ or $6.85 \mathrm{E}-4$ $\left(\mathrm{Ca}^{2+}\right)$, but with a Bonferroni correction, performed for 792 tests, the corrected $p$ value threshold is $6 \mathrm{E}-5$, and therefore none of the comparisons survive correction as they are at least an order of magnitude too high. A onetailed Wilcoxon rank-sum test based on the direction of effect from cohorts 1 and 2's FLX-VEH differences was used to assess differences in mean signal in the Contralateral and Ipsilateral ROls at end of stimulation. A one-tailed Wilcoxon rank-sum test was also used to assess differences in area under the curve (AUC) from the onset to end of stimulation between FLX and VEH groups. All pixel-by-pixel comparisons were Bonferroni corrected unless otherwise stated. A critical $\alpha$ of 0.05 was used for all tests to determine significance.

\section{Results}

\section{Resting-state hemodynamics remain unaltered following maternal FLX exposure}

To determine whether transient developmental FLX exposure can result in long-term alterations in functional connectivity observable in adulthood, we examined FLXexposed mice for changes in resting-state functional connectivity using an OIS imaging system. We assessed cortical activity in $\sim 45$ mice per condition, across five cohorts, using both direct measures of neuronal activity $\left(\mathrm{Ca}^{2+}\right.$ imaging, cohorts $\left.3-5\right)$ as well as hemodynamics (cohorts 1-5), representing the kind of indirect assessment that would be available in humans.

In the absence of a task or applied stimulus, correlation between individual cortical regions is used to operationally define resting-state functional connectivity independent of structural connectivity (Biswal et al., 1995). Specifically, functional connectivity between corresponding regions across hemispheres is high because of the regions' similar functions, as exemplified by the correlation between left and right motor areas. This homotopic contralateral functional connectivity (HCFC) can be assessed to identify disruption in disease models (Bauer et al., 2014). Comparison of HCFC between FLX and VEH groups (Fig. $1 C-F$ ) identified no significant alterations in the cortex: The $\mathrm{HbO}_{2} \mathrm{HCFC}$ patterns in FLX (Fig. 1C) and VEH (Fig. 1D) groups did not significantly diverge from each other in the $\mathrm{HbO}_{2}$ signal ( $t$ test, $p>0.05$ with Bonferroni correction; Fig. 1E,F). The GCaMP6f calcium data collected simultaneously with the hemodynamic data in cohorts 3-5 also showed a lack of significant difference (Fig. 1/,J) between FLX (Fig. 1G) and VEH (Fig. 1H) HCFC maps ( $t$ test, $p>0.05$ with Bonferroni correction). This finding confirmed that the similarity in FLX and VEH resting-state $\mathrm{HCFC}$ patterns seen in $\mathrm{HbO}_{2}$ were also reflected in calcium. Developmental FLX exposure therefore did not significantly alter resting-state HCFC as assessed by either hemodynamics or a more direct calcium-based measure of neural activity.

\section{Developmental FLX exposure alters stimulus- induced cortical hemodynamics and calcium activity}

Sensory aberrations such as altered behavioral responses to pain have previously been reported in neonates with prenatal SSRI exposure and the critical, transient $5 \mathrm{HT}$ role in the development of thalamocortical projections suggests that perception or management of sensory stimuli may be altered in individuals with perinatal FLX exposure (McCormick and Bal, 1994; Lebrand et al., 1996; Allen et al., 2017). To probe whether developmental FLX exposure alters sensory responsiveness to environmental stimuli, we therefore examined the evoked cortical response to a somatosensory stimulus. Left forepaw stimulation was applied to FLX and VEH mice in a block design, and changes in $\mathrm{HbO}_{2}$ and calcium signal were measured cortex-wide. The stimulation data of the GCaMP6fnegative cohorts 1 and 2 (Extended Data Fig. 2-1) were used to define ROls that were subsequently used to evaluate cohorts 3-5's $\mathrm{HbO}_{2}$ and calcium responses (Fig. 2). As expected, the observed region of greatest activation in all groups was the forepaw region of the somatosensory cortex, as defined by the cortical regions in the Paxinos histologic atlas (Franklin and Paxinos, 2008) and adapted to be a dorsal-view cortical map in White et al. (2011; Extended Data Fig. 2-2). $\mathrm{HbO}_{2}$ response at the end of the 10-s stimulation block ( $t=10 \mathrm{~s}$ ) identified ROls in both the contralateral and ipsilateral cortices, with the FLX group (Fig. $2 A$ ) displaying decreased $\mathrm{HbO}_{2}$ amplitude compared to the VEH controls (Fig. 2B) in the contralateral region focused over the stimulated somatosensory cortex (Fig. 2C,D). A comparative increase of $\mathrm{HbO}_{2}$ in ipsilateral cortex in FLX as compared to VEH is also evident at end of stimulation (Fig. 2D). As $\mathrm{HbO}_{2}$ is only an indirect measure of neural activity, this result could reflect either changes in neural activity or in hemodynamics. Therefore, we also examined calcium transients in our GCaMP6f cohorts. This decrease in contralateral activation and comparative increase in ipsilateral cortical activity during and immediately following stimulation was observed in the three GCaMP6f cohorts' calcium dynamics as well (Fig. $2 E-H)$, confirming that underlying neural activity is altered on somatosensory stimulation. Contralateral and ipsilateral ROls for analysis of cohorts 3-5 were defined by GCaMP-negative cohort 1 and 2's mean $\mathrm{HbO}_{2}$ maps, which displayed an increase in ipsilateral signal and decrease in contralateral signal within these ROls in FLX compared to VEH (Extended Data Fig. 2-1). Similarly, 

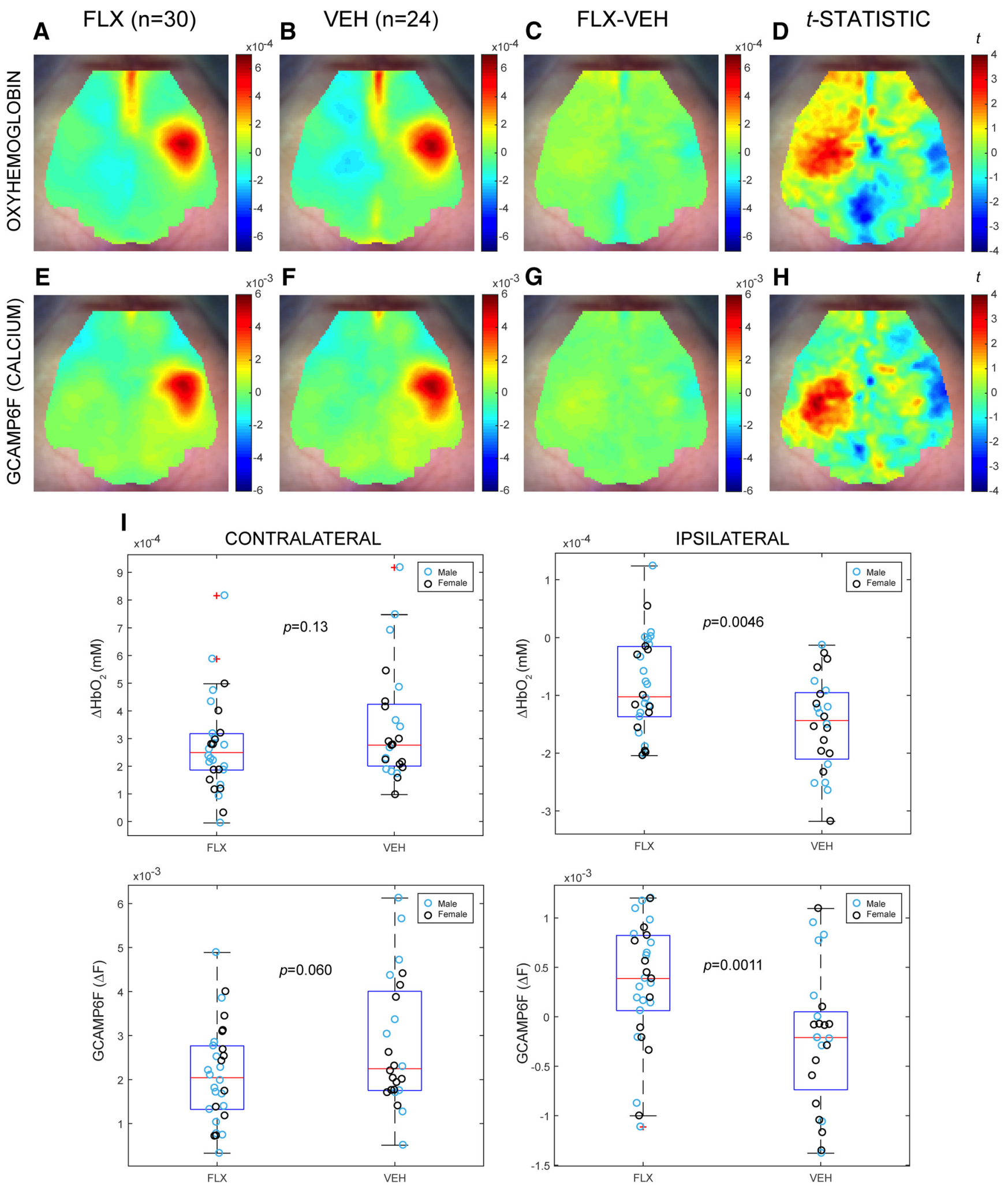

Figure 2. Mean $\mathrm{HbO}_{2}$ and calcium response to left forepaw stimulation at $t=10 \mathrm{~s}$ is decreased in FLX contralateral somatosensory cortex and increased in ipsilateral cortex. $\boldsymbol{A}, \boldsymbol{B}$, Map of mean $\mathrm{HbO}_{2}(\mathrm{mM})$ in $(\boldsymbol{A}) \mathrm{FLX}(n=30)$ and $(\boldsymbol{B})$ VEH $(n=24)$ groups. See Extended Data Figure 2-2 for the mean $\mathrm{HbO}_{2}$ activation map overlaid with cortical region boundaries as defined by the Paxinos atlas. $\boldsymbol{C}$, Mean difference between FLX and VEH HbO 2 maps (FLX-VEH). $\boldsymbol{D}$, $\boldsymbol{t}$ statistic map of FLX-VEH $\mathrm{HbO}_{2}$ (uncorrected). $\boldsymbol{E}, \boldsymbol{F}$, Map of mean GCaMP6f calcium signal $(\Delta \mathrm{F})$ in $(E) \mathrm{FLX}(n=30)$ and $(\boldsymbol{F}) \mathrm{VEH}(n=24)$ groups. $\boldsymbol{G}$, Mean difference between FLX and VEH calcium maps (FLX-VEH). $\boldsymbol{H}, t$ statistic map of FLX-VEH calcium groups (uncorrected). $\boldsymbol{I}$, Boxplots and scatterplots of $\mathrm{HbO}_{2}$ (first row) and GCaMP6f (second row) changes from baseline at $t=10 \mathrm{~s}$ in contralateral (left) and ipsilateral (right) ROls defined by the independent 
continued

dataset of cohorts 1 and 2 (see Extended Data Fig. 2-1 for ROI boundaries and the maps from cohorts 1 and 2 by which the ROls are defined). Sex of individuals within FLX and VEH groups indicated by blue (males) and black (females).

cohorts 3-5 displayed an increase in ipsilateral ROI signal in both contrasts (Wilcoxon rank-sum test; $\mathrm{HbO}_{2} \mathrm{p}=$ $0.0046, \mathrm{Ca}^{2+} p=0.0011$ ), although the contralateral ROI's decrease in both $\mathrm{HbO}_{2}$ and calcium signal was not significant (Wilcoxon rank-sum test; $\mathrm{HbO}_{2} p=0.13, \mathrm{Ca}^{2+}$ $p=0.060$; Fig. 2/). When animals of each sex were analyzed separately, the same significant increase in ipsilateral ROI signal was observed in males' $\mathrm{HbO}_{2}$ and calcium response as well as females' calcium signal (Wilcoxon rank-sum test; males $\mathrm{HbO}_{2} p=0.010, \mathrm{Ca}^{2+} p=$ 0.038 , females $\mathrm{HbO}_{2} p=0.13, \mathrm{Ca}^{2+} p=0.012$; Table 1). The reduction in $\mathrm{HbO}_{2}$ and calcium absolute signal amplitude in the ipsilateral response typically observed in VEH controls therefore demonstrates that developmental FLX exposure alters the strength of the cortical activity evoked by somatosensory stimulation.

\section{Developmental FLX exposure decreases cortical activation contralateral to the stimulated paw and reduces ipsilateral inhibition}

The analysis above defined regions that at a single time point, following stimulation, show differences between FLX and VEH groups in multiple cortical regions. We therefore reanalyzed the data from cohorts $3-5$ to determine whether this effect is consistent across time. Mean $\mathrm{HbO}_{2}$ and calcium activity of the two ROIs (contralateral and ipsilateral to the stimulated paw) were traced across the 60-s stimulation block. These regions were defined relative to the stimulated paw and included contralateral and ipsilateral ROls (Extended Data Fig. 2-1). FLX mice displayed a mean decrease in $\mathrm{HbO}_{2}$ signal amplitude compared to the VEH group in the contralateral ROI during the 10-s stimulation block (Fig. $3 A$ ). As the end of stimulation ( $t=10 \mathrm{~s}$ ) approached, absolute $\mathrm{HbO}_{2}$ signal amplitude in the ipsilateral $\mathrm{ROI}$ also decreased in the FLX group as compared to VEH (Fig. $3 A$ ). $\mathrm{HbO}_{2}$ AUC from the onset to end of stimulation for the contralateral and ipsilateral ROls were both significantly different in the FLX mice compared to VEH (Wilcoxon rank-sum test; contralateral AUC $p=0.050$, ipsilateral AUC $p=0.043$; Fig. $3 D$ ). This AUC finding was replicated in the calcium signal, which displayed significant differences in both ROls (Wilcoxon rank-sum test; contralateral AUC $p=0.028$, ipsilateral AUC $p=0.014$; Fig. 3B-D). Although not deliberately powered for analysis by sex, when analyzed separately, males displayed a significant decrease in both the $\mathrm{HbO}_{2}$ and calcium contralateral response magnitude (AUC of the contralateral ROI response), while females did not display a significant decrease in $\mathrm{HbO}_{2}$ contralateral response magnitude (contralateral ROI AUC in the $\mathrm{HbO}_{2}$ signal, Wilcoxon rank-sum test; males $\mathrm{HbO}_{2}$ contralateral AUC $p=0.031, \mathrm{Ca}^{2+} p=0.034$, females contralateral $\mathrm{HbO}_{2}$ AUC $p=0.12, \mathrm{Ca}^{2+} p=0.32$; Extended Data Fig. $3-1$; Table 1). In the ipsilateral ROI response, FLX and VEH groups analyzed as distinct male or female populations were not significantly different but females displayed a trend toward increased ipsilateral ROI AUC in the $\mathrm{HbO}_{2}$ signal and demonstrated a significant increase in ipsilateral AUC response in the calcium signal (Wilcoxon ranksum test; males $\mathrm{HbO}_{2}$ ipsilateral AUC $p=0.15, \mathrm{Ca}^{2+} p=$ 0.34 , females $\mathrm{HbO}_{2}$ ipsilateral AUC $p=0.075, \mathrm{Ca}^{2+} p=$ 0.0042; Extended Data Fig. 3-1; Table 1). These results confirmed that the differences in signal intensity observed at the end of the 10-s stimulation block were consistently observed across time during the application of the somatosensory stimulus. Of particular note, the calcium and hemodynamic signals display the same gross difference across time and suggest that $\mathrm{HbO}_{2}$ is indeed reflecting an underlying neural deficit.

\section{Abnormalities in $\mathrm{HbO}_{2}$ and calcium evoked response co-localize in the cortex \\ While the calcium and hemodynamic signals both dif-} fered significantly in the same direction within the two ROls described, it was unclear whether abnormalities in $\mathrm{HbO}_{2}$ and GCaMP6f would occur together in other cortical areas. We therefore evaluated if the calcium and hemodynamic signals spatially co-localized in areas outside of the two ROls by overlaying binary cortical maps for each contrast that represented each pixel where there was a significant FLX-VEH difference $(p<0.05$, uncorrected; Fig. 4). $\mathrm{HbO}_{2}$ and calcium displayed an overlapping area of strong FLX-VEH difference in contralateral cortex and a co-localization region in ipsilateral cortex of $\sim 1.5 \mathrm{~mm}^{2}$. This suggests that the two contrasts overall show similar activation patterns in response to somatosensory stimulation.

\section{Discussion}

Overall, the changes observed in evoked response but not functional connectivity in this mouse model of perinatal or developmental SSRI exposure suggest that sensory information processing is more strongly affected by this environmental influence than resting state functional connectivity is. The lack of significant difference in homotopic contralateral functional connectivity that we found suggests that the correlation structure in baseline hemodynamic and neuronal dynamics are largely undisturbed in the FLX mouse cortex. This lack of significant result may also reflect, however, the severity or variability in phenotype that results from perinatal SSRI exposure. With a relatively large sample size of $\sim 40$ mice per group, it would be reasonable to expect that even a relatively small effect would be identified. However, perinatal SSRI exposure in humans, if it does contribute to risk beyond maternal diagnosis, has a modest effect size and thus does not lead to a diagnosis of psychiatric illness or other neurodevelopmental conditions in a high percentage of cases (Malm et al., 2016; Gingrich et al., 2017). If mice also show this variable penetrance, then future studies might leverage a behavioral variable or other metric to stratify data for further analysis. 
A

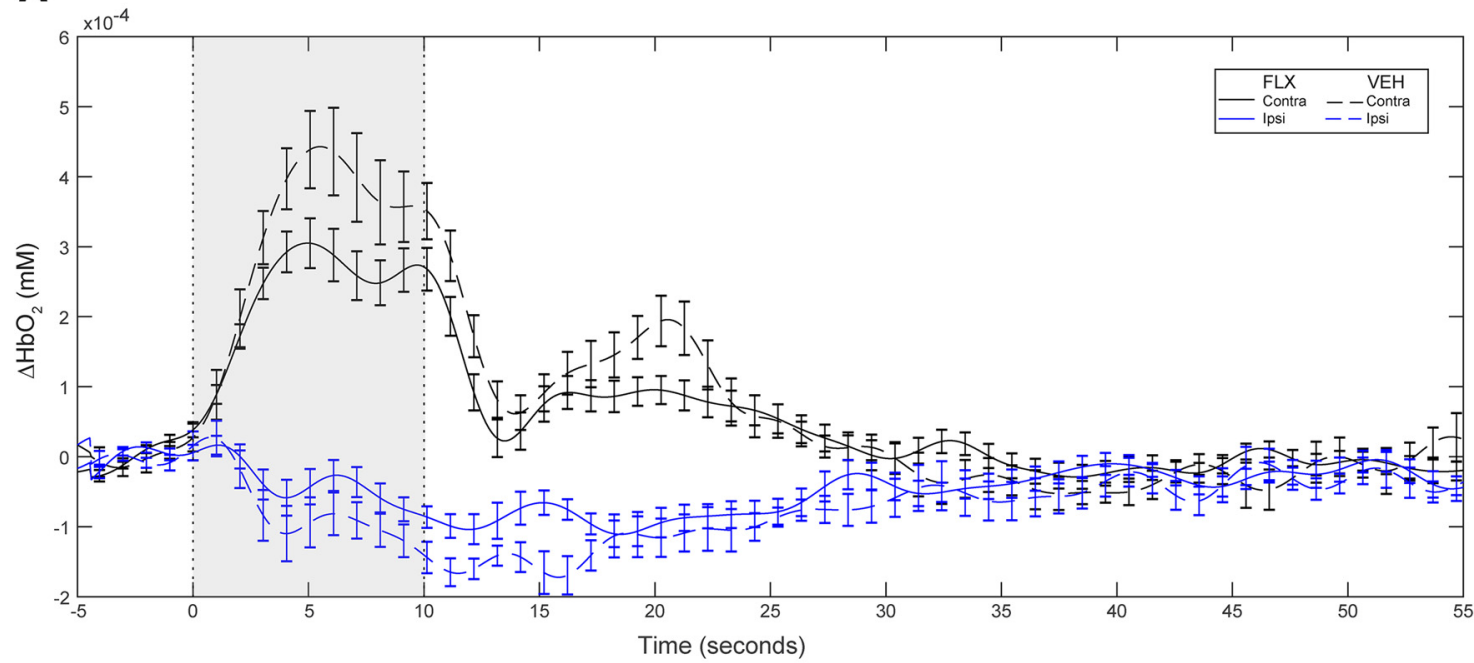

B

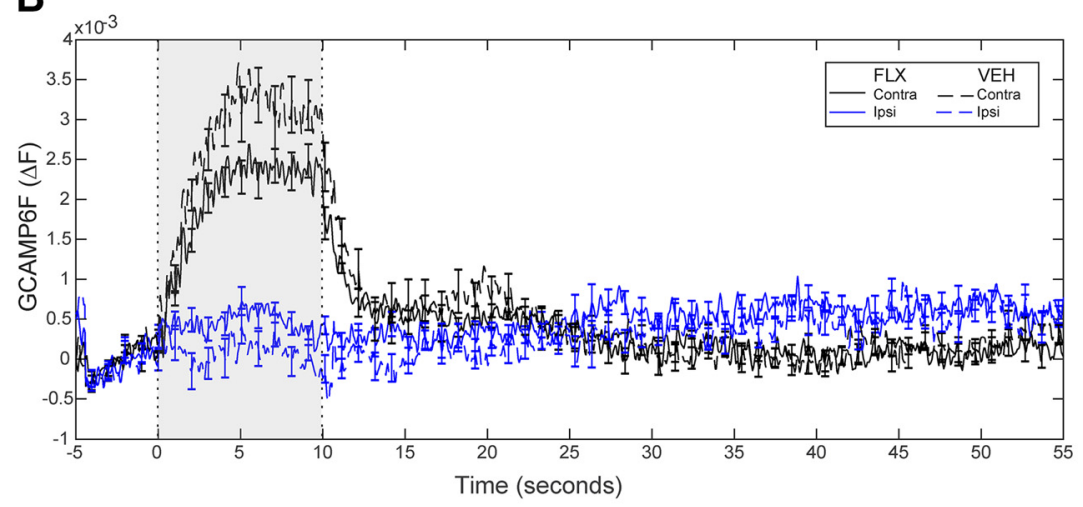

C

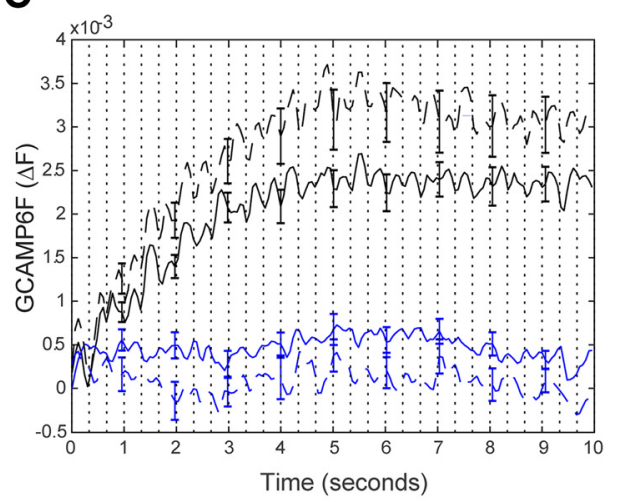

D CONTRALATERAL
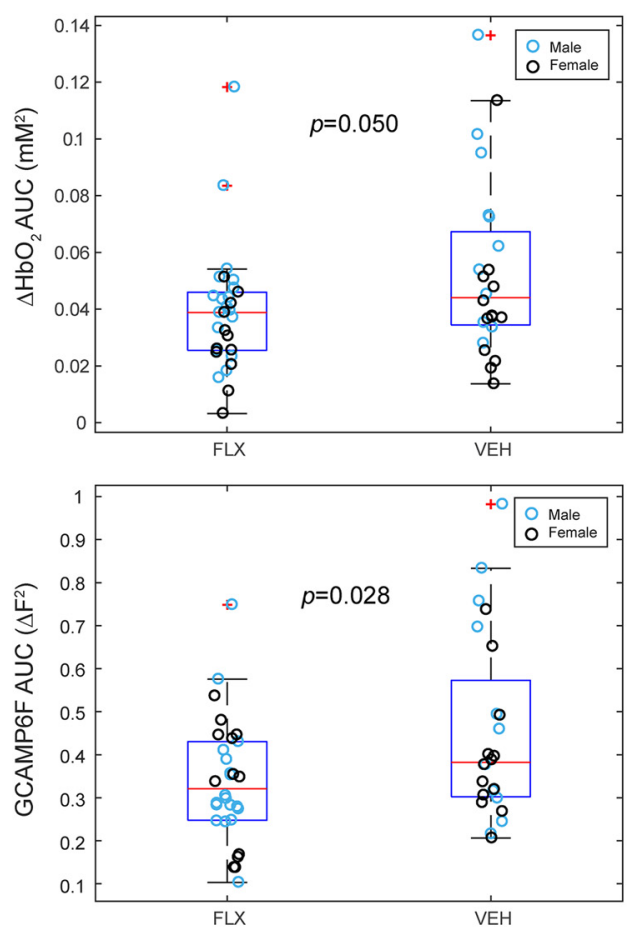

IPSILATERAL
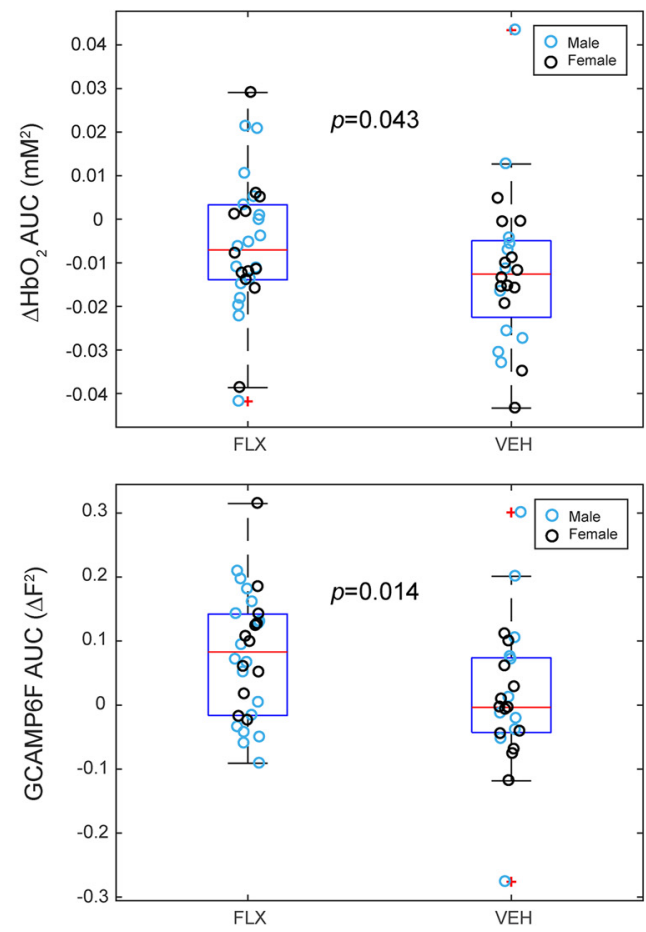

Figure 3. $\mathrm{HbO}_{2}$ and $\mathrm{Ca}^{2+}$ response amplitude is decreased in $\mathrm{ROI}$ contralateral to stimulated forepaw and altered in ipsilateral $\mathrm{ROI}$. 
continued

$\boldsymbol{A}$, Block-averaged time trace of mean $\Delta \mathrm{HbO}_{2}$ response to forepaw stimulation in each ROI (FLX $n=30$, VEH $n=24$; black $=$ contralateral, blue $=$ ipsilateral). Left forepaw stimulation at $3 \mathrm{~Hz}$ applied $t=0 \mathrm{~s}$ to $t=10 \mathrm{~s}$. B. Block-averaged time trace of GCaMP6 $\mathrm{Ca}^{2+}$ response to forepaw stimulation in each $\mathrm{ROI}(\mathrm{FLX} n=30$, VEH $n=24$; black $=$ contralateral, blue = ipsilateral). Left forepaw stimulation at $3 \mathrm{~Hz}$ applied $t=0 \mathrm{~s}$ to $t=10 \mathrm{~s}$. C. Detail of block-averaged time trace of mean GCaMP6 Ca ${ }^{2+}$ response to forepaw stimulation during time of stimulation $(t=0-10 \mathrm{~s}$; FLX $n=30, \mathrm{VEH} n=24)$. Vertical black lines represent timing of 3-Hz stimulus presentation. $\boldsymbol{D}$, Boxplots and scatterplots of $\mathrm{HbO}_{2}$ (first row) and GCaMP6f (second row) AUC for contralateral (left) and ipsilateral (right) cortical ROls during stimulation ( $t=0-10 \mathrm{~s}$ ). Sex of individuals within FLX and VEH groups indicated by blue (males) and black (females). See Extended Data Fig. 3-1 for block-averaged time traces separated by sex.

In contrast to the resting state analysis, the abnormalities observed in cortical response to forepaw stimulation showed a reliable effect, detectable across three cohorts. This suggests that perinatal SSRI exposure alters sensory processing or gating in a way that has lasting repercussions observable even in adulthood. The reduced response in cortex contralateral to the stimulated paw as well as reduced negative ipsilateral signal during stimulation trials indicates that somatosensory inputs are abnormally received or processed in the cortex. The abnormal cortical response in ipsilateral cortex suggests reduced inhibition, which may be caused by thalamocortical dysfunction linked to morphologic abnormalities previously reported in the literature from SSRI exposure (Lee and Lee, 2012). Suppression of activity in ipsilateral somatosensory cortex during stimulus presentation plays a role in the successful execution of sensory gating (Staines et al., 2002) and, by extension, the ability to process and react to sensory stimuli in an organism's environment as needed. Abnormal ipsilateral cortical inhibition suggests that developmental SSRI exposure causes long-term sensory gating and processing abnormalities. The left forepaw was exclusively stimulated in these assays, but similar effects would be expected if right forepaw was stimulated instead, due to the equal number of left-handed and right-handed individuals in the C57BI/6J population (Collins, 1968).

Finally, the abnormalities in cortical response following perinatal SSRI exposure we detected suggest that $\mathrm{HbO}_{2}$ and GCaMP calcium dynamics during somatosensory stimulation are coupled temporally and spatially across the cortex. During stimulation, both contrasts displayed a loss of signal amplitude in contralateral $\mathrm{ROI}$ and abnormalities in ipsilateral cortex. The cortical regions with the largest FLX-VEH differences in $\mathrm{HbO}_{2}$ and calcium also displayed significant overlap at the end of stimulation. This suggests that altered neurovascular coupling is not the immediate underlying cause for the $\mathrm{HbO}_{2}$ deficits we observe following perinatal SSRI exposure. Future studies might leverage this finding as added confirmation that hemodynamic methods or blood oxygen level-dependent methods in humans are a valid way to examine neural activity in 5HT dysfunction or following early SSRI exposure in humans or mammalian experimental systems.

This abnormal cortical response to somatosensory stimulation following perinatal FLX exposure that we have described here appears to reflect and further characterize the same underlying phenomenon as other deficits reported in the literature. Early SSRI exposure in rodents has previously been linked to long-term morphologic changes to both the somatosensory cortex and thalamocortical afferents to the region (Lee, 2009; Smit-Rigter et al., 2012). Alterations in somatosensory-related behaviors have also been observed (Lee, 2009; Maloney et al., 2018), but behavior phenotypes are complex and difficult to directly link to neural alterations. This functional neuroimaging phenotype, which suggests sensory gating or processing abnormalities on a circuit level, helps bridge the gap between morphologic and behavioral effects of perinatal SSRI exposure.

We used both sexes of animals so that our results would be more generalizable, and although our study was not deliberately powered for analysis by sex, post hoc the trends seen in the evoked response to forepaw stimula-
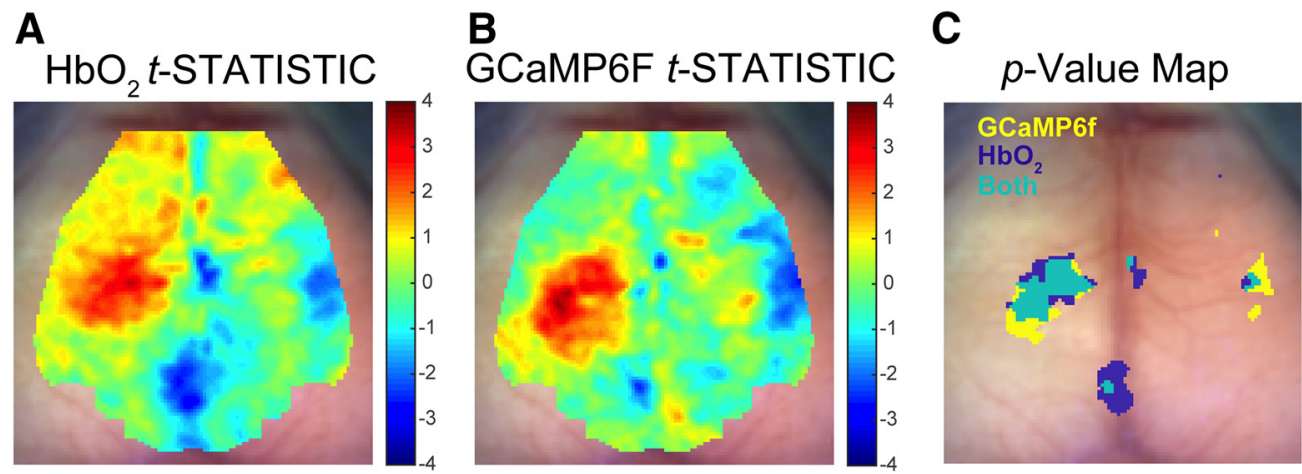

Figure 4. Increases in FLX mice's $\mathrm{HbO}_{2}$ and calcium response co-localize in cortex ipsilateral to forepaw stimulation. $\boldsymbol{A}$, $\mathrm{HbO}$ $t$ statistic map of FLX-VEH (uncorrected; FLX $n=30$, VEH $n=24$ ). B, GCaMP6f $t$ statistic map of FLX-VEH (uncorrected; FLX $n=30, \mathrm{VEH} n=24)$. C , Overlay figure of $\mathrm{HbO}_{2}$ and GCaMP6f uncorrected $p<0.05$ maps $\left(\right.$ blue $=\mathrm{HbO}_{2}$, yellow $=\mathrm{GCaMP6f}$, green $=$ both). 
tion suggest that female and male brains respond similarly to perinatal SSRI exposure. It is true that in both the hemodynamic and calcium measures, differences in males' contralateral response and females' ipsilateral response appeared more prominent, suggesting that further studies focused on sex differences could be a promising research direction. Limitations of this study also provide avenues for further research into the effects of perinatal SSRI exposure. Although necessary for our forepaw stimulation paradigm, imaging mice under the effects of anesthesia may introduce confounds to neuroimaging results (Wright et al., 2017), and therefore a study of resting-state dynamics or evoked response in wakefulness using visual or whisker stimulation (Berwick et al., 2002; Martin et al., 2013; Carandini et al., 2015; Xiao et al., 2017) could identify functional neurophenotypes that we were underpowered to observe. In addition, we documented the effects of perinatal SSRI exposure in adulthood, but performing similar neuroimaging assays at earlier timepoints during development (Kozberg et al., 2016) would help elucidate the developmental trajectory of these functional abnormalities and potentially serve as a biomarker to determine what portion of the exposed population may develop long-term deficits. Comparison of individuals' somatosensory stimulation response in the cortex with their performance on tactile behavioral assays such as the von Frey test of somatosensation should also be considered, as it has previously been shown to be sensitive to developmental SSRI exposure perturbations (Maloney et al., 2018), and has the potential to provide insights into individual variability in populations developmentally exposed to SSRIs. In future studies it will be important to consider using functional MRI in mice, to evaluate whether these OIS hemodynamic findings are replicated using fMRl's BOLD signal and potentially explore subcortical elements of the circuit in which the abnormal evoked somatosensory response was observed. Future functional neuroimaging studies in awake mice or at earlier stages in development would provide important information on the long-term effects of perinatal SSRI exposure or other genetic and environmental perturbations affecting neurodevelopment.

Taken together, our findings provide evidence that perinatal SSRI exposure causes long-term functional deficits observable in the brain in adulthood. While we did not observe changes in resting-state dynamics between homotopic contralateral regions, cortical response to somatosensory stimulation was altered in FLX mice. The observed altered responses in both cortical hemispheres after perinatal exposure to an SSRI suggest that the evoked cortical response is both diminished in magnitude and slightly shifted spatially compared to the response in the healthy brain, and bridges the morphologic and behavioral phenotypic abnormalities previously seen in models of early SSRI exposure.

\section{References}

Albert NB, Robertson EM, Miall RC (2009) The resting human brain and motor learning. Curr Biol 19:1023-1027.

Allen AE, Procyk CA, Brown TM, Lucas RJ (2017) Convergence of visual and whisker responses in the primary somatosensory thal- amus (ventral posterior medial region) of the mouse: visual responses in the somatosensory thalamus. J Physiol 595:865-881.

Ansorge MS (2004) Early-life blockade of the 5-HT transporter alters emotional behavior in adult mice. Science 306:879-881.

Bauer AQ, Kraft AW, Wright PW, Snyder AZ, Lee J-M, Culver JP (2014) Optical imaging of disrupted functional connectivity following ischemic stroke in mice. Neuroimage 99:388-401.

Berwick J, Martin C, Martindale J, Jones M, Johnston D, Zheng Y, Redgrave P, Mayhew J (2002) Hemodynamic response in the unanesthetized rat: intrinsic optical imaging and spectroscopy of the barrel cortex. J Cereb Blood Flow Metab 22:670-679.

Biswal B, Yetkin FZ, Haughton VM, Hyde JS (1995) Functional connectivity in the motor cortex of resting human brain using echo-planar MRI. Magn Reson Med 34:537-541.

Bonnin A, Torii M, Wang L, Rakic P, Levitt P (2007) Serotonin modulates the response of embryonic thalamocortical axons to netrin-1. Nat Neurosci 10:588-597.

Carandini M, Shimaoka D, Rossi LF, Sato TK, Benucci A, Knöpfel T (2015) Imaging the awake visual cortex with a genetically encoded voltage indicator. J Neurosci 35:53-63.

Collins RL (1968) On the inheritance of handedness. J Hered 59:912.

Cooper WO, Willy ME, Pont SJ, Ray WA (2007) Increasing use of antidepressants in pregnancy. Am J Obstet Gynecol 196:544.e1-5.

Ferron JF, Kroeger D, Chever O, Amzica F (2009) Cortical inhibition during burst suppression induced with isoflurane anesthesia. $\mathrm{J}$ Neurosci 29:9850-9860.

Franklin K, Paxinos G (2008) The mouse brain in stereotaxic coordinates, Ed 3. Amsterdam; New York: Elsevier/Academic Press.

Gingrich JA, Malm H, Ansorge MS, Brown A, Sourander A, Suri D, Teixeira CM, Caffrey Cagliostro MK, Mahadevia D, Weissman MM (2017) New insights into how serotonin selective reuptake inhibitors shape the developing brain: SSRI effects on the fetus. Birth Defects Res 109:924-932.

Hanley GE, Brain U, Oberlander TF (2015) Prenatal exposure to serotonin reuptake inhibitor antidepressants and childhood behavior. Pediatr Res 78:174-180.

Hansen HH, Sánchez CS, Meier E (1997) Neonatal administration of the selective serotonin reuptake inhibitor Lu 10-134-C increases forced swimming-induced immobility in adult rats: a putative animal model of depression? J Pharmacol Exp Ther 283:1333-1341.

Kozberg MG, Ma Y, Shaik MA, Kim SH, Hillman EMC (2016) Rapid postnatal expansion of neural networks occurs in an environment of altered neurovascular and neurometabolic coupling. J Neurosci 36:6704-6717.

Lebrand C, Cases O, Adelbrecht C, Doye A, Alvarez C, El Mestikawy S, Seif I, Gaspar P (1996) Transient uptake and storage of serotonin in developing thalamic neurons. Neuron 17:823-835.

Lee LJ (2009) Neonatal fluoxetine exposure affects the neuronal structure in the somatosensory cortex and somatosensory-related behaviors in adolescent rats. Neurotox Res 15:212-223.

Lee LJ, Lee LH (2012) Neonatal fluoxetine exposure alters motor performances of adolescent rats. Dev Neurobiol 72:1122-1132.

Linde K, Kriston L, Rücker G, Jamil S, Schumann I, Meissner K, Sigterman KS (2015) Efficacy and acceptability of pharmacological treatments for depressive disorders in primary care: systematic review and network meta-analysis. Ann Fam Med 13:69-79.

Liu X, Agerbo E, Ingstrup KG, Musliner K, Meltzer-Brody S, Bergink $\mathrm{V}$, Munk-Olsen T (2017) Antidepressant use during pregnancy and psychiatric disorders in offspring: Danish nationwide register based cohort study. BMJ 358:j3668.

Lugo-Candelas C, Cha J, Hong S, Bastidas V, Weissman M, Fifer WP, Myers M, Talati A, Bansal R, Peterson BS, Monk C, Gingrich JA, Posner J (2018) Associations between brain structure and connectivity in infants and exposure to selective serotonin reuptake inhibitors during pregnancy. JAMA Pediatr 172:525-533.

Lupattelli A, Wood M, Ystrom E, Skurtveit S, Handal M, Nordeng H (2018) Effect of time-dependent selective serotonin reuptake inhibitor antidepressants during pregnancy on behavioral, emo- 
tional, and social development in preschool-aged children. J Am Acad Child Adolesc Psychiatry 57:200-208.

Ma Y, Shaik MA, Kozberg MG, Kim SH, Portes JP, Timerman D, Hillman EMC (2016) Resting-state hemodynamics are spatiotemporally coupled to synchronized and symmetric neural activity in excitatory neurons. Proc Natl Acad Sci USA 113:E8463-E8471.

Malm H, Brown AS, Gissler M, Gyllenberg D, Hinkka-Yli-Salomäki S, McKeague IW, Weissman M, Wickramaratne P, Artama M, Gingrich JA, Sourander A (2016) Gestational exposure to selective serotonin reuptake inhibitors and offspring psychiatric disorders: a national register-based study. J Am Acad Child Adolesc Psychiatry 55:359-366.

Maloney SE, Akula S, Rieger MA, McCullough K, Chandler K, Corbett AM, McGowin AE, Dougherty JD (2018) Examining the reversibility of long-term behavioral disruptions in progeny of maternal SSRI exposure. eNeuro 5:ENEURO.0120-18.2018.

Marken PA, Munro JS (2000) Selecting a selective serotonin reuptake inhibitor: clinically important distinguishing features. Prim Care Companion J Clin Psychiatry 2:205-210.

Martin C, Zheng Y, Sibson NR, Mayhew JEW, Berwick J (2013) Complex spatiotemporal haemodynamic response following sensory stimulation in the awake rat. Neuroimage 66:1-8.

McCormick DA, Bal T (1994) Sensory gating mechanisms of the thalamus. Curr Opin Neurobiol 4:550-556.

Mitchell AA, Gilboa SM, Werler MM, Kelley KE, Louik C, HernándezDíaz S (2011) Medication use during pregnancy, with particular focus on prescription drugs: 1976-2008. Am J Obstet Gynecol 205:51.e1-8.

Oberlander TF, Eckstein Grunau R, Fitzgerald C, Ellwood A-L, Misri S, Rurak D, Riggs KW (2002) Prolonged prenatal psychotropic medication exposure alters neonatal acute pain response. Pediatr Res 51:443-453.

Oberlander TF, Grunau RE, Fitzgerald C, Papsdorf M, Rurak D, Riggs W (2005) Pain reactivity in 2-month-old infants after prenatal and postnatal serotonin reuptake inhibitor medication exposure. Pediatrics 115:411-425.

Oberlander TF, Reebye P, Misri S, Papsdorf M, Kim J, Grunau RE (2007) Externalizing and attentional behaviors in children of depressed mothers treated with a selective serotonin reuptake inhibitor antidepressant during pregnancy. Arch Pediatr Adolesc Med 161:22-29.

O'Connell KS, McGregor NW, Lochner C, Emsley R, Warnich L (2018) The genetic architecture of schizophrenia, bipolar disorder, obsessive-compulsive disorder and autism spectrum disorder. Mol Cell Neurosci 88:300-307.

Olivier JDA, Akerud H, Kaihola H, Pawluski JL, Skalkidou A, Högberg U, Sundström-Poromaa I (2013) The effects of maternal depression and maternal selective serotonin reuptake inhibitor exposure on offspring. Front Cell Neurosci 7:73.

Rotem-Kohavi N, Williams LJ, Virji-Babul N, Bjornson BH, Brain U, Werker JF, Grunau RE, Miller SP, Oberlander TF (2019) Alterations in resting state networks following in utero selective serotonin reuptake inhibitor exposure in the neonatal brain. Biol Psychiatry Cogn Neurosci Neuroimaging 4:39-49.

Smit-Rigter LA, Noorlander CW, von Oerthel L, Chameau P, Smidt MP, van Hooft JA (2012) Prenatal fluoxetine exposure induces life-long serotonin $5-\mathrm{HT}_{3}$ receptor-dependent cortical abnormalities and anxiety-like behaviour. Neuropharmacology 62:865-870.

Sodhi MS, Sanders-Bush E (2004) Serotonin and brain development. Int Rev Neurobiol 59:111-174.

Staines WR, Graham SJ, Black SE, Mcllroy WE (2002) Task-relevant modulation of contralateral and ipsilateral primary somatosensory cortex and the role of a prefrontal-cortical sensory gating system. Neuroimage 15:190-199.

Videman M, Tokariev A, Saikkonen H, Stjerna S, Heiskala H, Mantere O, Vanhatalo $S$ (2017) Newborn brain function is affected by fetal exposure to maternal serotonin reuptake inhibitors. Cereb Cortex 6:3208-3216.

Vitalis T, Parnavelas JG (2003) The role of serotonin in early cortical development. Dev Neurosci 25:245-256.

Wai MSM, Lorke DE, Kwong WH, Zhang L, Yew DT (2011) Profiles of serotonin receptors in the developing human thalamus. Psychiatry Res 185:238-242.

White BR, Bauer AQ, Snyder AZ, Schlaggar BL, Lee J-M, Culver JP (2011) Imaging of functional connectivity in the mouse brain. PLoS One 6:e16322.

Wright PW, Brier LM, Bauer AQ, Baxter GA, Kraft AW, Reisman MD, Bice AR, Snyder AZ, Lee J-M, Culver JP (2017) Functional connectivity structure of cortical calcium dynamics in anesthetized and awake mice. PLoS One 12:e0185759.

Xiao D, Vanni MP, Mitelut CC, Chan AW, LeDue JM, Xie Y, Chen AC, Swindale NV, Murphy TH (2017) Mapping cortical mesoscopic networks of single spiking cortical or sub-cortical neurons. Elife 6:e19976.

Zhang H, Long Z, Ge R, Xu L, Jin Z, Yao L, Liu Y (2014) Motor imagery learning modulates functional connectivity of multiple brain systems in resting state. PLoS One 9:e85489. 